\title{
Challenges of the dialog between humanization of health and medicine for the assistance to woman health in the Brazilian scenario
}

\author{
Denise Ribeiro Barreto Mello*, Ligia Costa Leite \\ Faculdade de Medicina de Campos, Universidade Federal do Rio de Janeiro, Rio de Janeiro, Brasil; \\ *Corresponding Author: deniserbmello@gmail.com
}

Received 6 June 2013; revised 6 July 2013; accepted 31 July 2013

Copyright (C) 2013 Denise Ribeiro Barreto Mello, Ligia Costa Leite. This is an open access article distributed under the Creative Commons Attribution License, which permits unrestricted use, distribution, and reproduction in any medium, provided the original work is properly cited.

\begin{abstract}
The present article aims to present, by a bibliographic review, the current challenges of the dialog among fundamental issues referring to humanization as for current public policy in Brazilian scenario. The first one concerns with national health humanization policies and ultimately the humanization of the assistance to the woman's health, especially at delivery and child birth. Using the hermeneutic dialectic as methodology, it's understood that having these three facets, dialog consists not only of a great challenge but also of a condition on being put into practice, and expected issues become an effective reality.
\end{abstract}

Keywords: Medical Education; Humanization of Assistance; Medical Cares; Women Health

\section{INTRODUCTION}

“There weren't enough beds, awful environmental conditions, use of contaminated material, and inevitable contagion", this picture may look so common and up to date, but it has to do with the first registries of the conditions of several hospitals visited by Tenon and Howard in France and England between 1775 and 1780 [1]. The concern was to shift the hospitals into places which were less "sickness bringers", and which for some time were used as shelters for those who put the hygiene of the city at risk.

This historical issue reveals that the concerns around the quality of the assistance are not a novelty, it's recurrent and, nowadays, in the Brazilian reality it is a part of a Brazilian public policy of humanization of the health system. There's also at the same time, a big discussion which is weaved around the humanization of medicine which had an inverted movement. The doctor has always been associated to care, consolation, much more than a therapeutical one, yet this care was destined to the rich and wealthy. Primum no nocere (not damaging before anything else), Hippocrates' expression, considered the father of medicine since Ancient Greece, shows that the doctor's role was on top of all, the one minimizing the suffering in the clinic performance of hearing the complaints, listening to the reports of pain, and performing physical checkups in order to establish an approach for the treatment.

The $21^{\text {st }}$ century witnessed the great advance caused by the development of high technology after the surge and the development of the computers and, today, the technology allows us not only to see the human body from inside in details, but also to see it in its working process.

All that has allowed an increasingly growth of life expectancy, the so called longevity, the discovery and the cure of many sicknesses, and the softening of the damages caused by pathologies which don't have a definitive cure yet, such as AIDS. The provided benefits to mankind by the technologic advent are undeniable. However, to what extent has all this advance helped in the improvement of the quality assistance, especially the assistance to the woman health concerning the childbirth and the delivery?

Especially taking humanization of health, medicine and its effects on the assistance to woman health in the childbirth and the delivery as the object for this article, it fits perfectly here an analysis of the reached advances and the blockers to its evolution: after more than ten years of the promulgation of the National Program of Humanization and Hospital Assistance, (NPHHA) [2], which 
evolves to NPH in 2003, was an important step even to the elaboration in 2001 of the document "Childbirth, abortion and child killing: humanized assistance to woman" [3] and, in 2002, "Program of Humanization of Delivery, Humanization in the Prenative and the Childbirth" [4]. All of them were elaborated, developed and made possible by the Health Ministry.

This is so because we realize that with similar objects and objectives, the policies and the programs seem to go independently in the theoretical, clinic and epistemological fields.

If those facets of the humanization seem to have obvious connections, based on our theoretical findings in this study, we can affirm that being put into practice they are dissociated and even follow their ways independently. We humanize by inserting professionals of different areas into the hospitals, improving the ambience, developing more cordial and cozier postures. But neuralgic issues keep untouched. At the maternities, mothers breastfeed their babies together with those mothers who have a dead child. Because of this and other day-by-day situations in the Brazilian public maternities, we propose to discuss the necessity to reflect over the humanization of medicine for the effectiveness of the national policies of humanization of health, mainly those ones referring directly to woman care with the assistance to childbirth and delivery.

Therefore, going from this great area of our interest, this study aims to analyze the possible articulations of the health field and of the medicine and its ideals of humanization, especially, its interface with the Field of obstetrics in which the care for the pregnant woman is concentrated, and which is necessary in the formation of the doctor and the discourse of the importance of humanization into the doctor-patient relationship.

For that objective, a bibliographic review was performed articulating the analysis of the context in the changes which have been proposed to the medical courses, keeping ourselves to the humanization of the delivery and the childbirth, important topic into the Obstetrics subject. In a general way, those changes emerge from the current criticism to the overuse of technology and the almost exclusive development of the technical competence provided by the curricular structure of the courses. The most direct and visible consequence of this process is the distancing of the doctor, reduced to the level of a technician, who aims to take care of a sick organ and refuses the relationship/meeting with the sickened person. In the context of the woman health, this picture brings about a difficult consequence to deal with. Once the care with the woman requires necessarily the consideration of psychosocial and gender aspects, issues which are not inscribed into the technological universe but on the other hand into the ethic, aesthetic, social, cultural, psychological and an- thropologic universe.

To reach our goals, we shall use the hermeneutic-dialectic method proposed by Minayo [5] to highlight the complementarities and oppositions between the two facets of humanization, for this methodology constituted as an important way of thinking to fundamentally qualitative studies which take into account the subjectivity and may create parameters for analysis. Such ways are of extensive spectrum in the interaction between hermeneutics and dialectics: both go from the previous knowledge that there's no neutrality in studies and that the comprehension and the criticism go over the technique; both go beyond the tasks and are more than simple tools for the thinking and, ultimately, are referred to the instituted practice to the power and the common sense [5].

\section{HUMANIZATION OF HEALTH: CONCEPT AND PROBLEMATIZING}

By the year 2000, the $9^{\text {th }}$ National Health Conference was held in Brazil. The title is: "Brazil saying how it wants to be treated effectuating SUS: access, quality and humanization in the attention to health with social control" [6]. Out of it the National Program of Humanization and Hospital Assistance (NPHHA) was derived in 2000 [2], whose objectives were directed to the perfecting of relationships between the users and the health system represented by the professionals and the services provided by them, aiming to improve the quality and effectiveness of the services in the environment of SUS.

In 2001, already inscribed into those change processes of the health scenarios and humanitarian principles, the Health Ministry announced the official document inscribed in the environment of the health policies, the title is: "Childbirth, abortion and child killing: humanized assistance to woman" [3]. Following this one there was in 2002, "Program of Humanization of delivery. Humanization in the pre-native and the childbirth" [4], with the same contents and of operational character, whereas the first one offers principles and proper lightings to the implementation and effectiveness of policies.

In 2003, National Policy of Humanization [7] (NPH) was consolidated, under the title "Humanizing SUS: the humanization as the guiding axis of the practices of attention and management in all the instances of SUS" which, having similar objectives to NPHHA, goes further in important issues as better delimitating the category actions, defining general strategies, guiding principles and delimitating priorities.

Initially the NPH problematizes the concept of humanization: "And why to talk about humanization when the established relationships in the process of health care happen among humans? We would be willing to "make the relationship with the user more human" with such concept, just giving the services very small detailings, 
but leaving the conditions of the production of work in health untouched?" [7].

According to this statement, the reflexion about humanization implies fundamentally into the need of undoing the misunderstanding around the concept of humanization which puts as essentially human practices, what is agreeable and what is the opposite of it (anger, aggressiveness, violence) as something inhuman. If we agree with Nietzsche that we are human beings who are excessively human and thus we'll never be totally good, such conception will not be supported [8].

Either good or bad, all the human actions belong to the human, for they are the product and producer of social relationships, way from which they can opt to give out or not to give out the best of themselves. The human is the dialectic assembling of social relationships and without the dichotomy between the good (human) and the bad (inhuman) [9]. It is not therefore, an abstraction, but on the other way around it is an action that, aimed at people, necessarily brings about a check point of ethics, involving finality, the potential and direction of this movement.

In the Brazilian scenario the discussions about humanization aim to overcome the current dichotomies, searching to articulate technological inseams with relationship Technologies, better saying, ways of care which value the listening, the dialog, the welcoming, without overlooking the benefits of technology, knowledge and techniques.

The development of the policies around humanization implies necessarily in the recognition of health as a right and also the quality of assistance and, yet it evokes humanistic values (respect, cordiality, solidarity and generosity) it is not limited to them, which are implicit to the notion of humanism. The guiding principles of humanization aim to rescue, from a critic reflexion, such values as actions in the day-by-day practices of health in the institutional level, by the health professionals.

The humanization may be understood, according to its status quo, in five different ways: as a principle of humanistic and ethic basis, rescuing respect, the human valuing and dignity, with special emphasis upon the human values; as a movement opposed to the institutional violence that is operated by the imposing of tough rules and inflexible structures, both to the users and professionals; as a public policy of attention into the management of SUS and, in this context, constituted as an important tool to guarantee the protagonism of different actors and subjects of co participative management; as a methodology, once humanization does not come true only in the field of ideas and reflections, but can only come true in the field of practices; and as for technology of care into the assistance which poses as extremely necessary its association to the techniques by involving the ethic and rela- tionship dimensions related and, many times, determining of this process [10].

The proposal of humanization first appeared, among other determiners, as a response to one opposing to institutional violence [11] (understood as cancelling out of subjects in collective contexts) which is developed in several levels in the ambiance of health, practically speaking as a technical demand, either it is physical, psychological or symbolic [12,13].

There are explicit ways of violence in the contexts of health: physical (by invasive attitudes to which the patients have to go through), symbolic (by affecting them either morally or ethically), or behavioral (insensitivity, brutality, carelessness, words which cause constraint). But there are also kinds of violence which operate by other disguises, more difficult to be perceived and have been named as silent violence by Leite [14]. For the author, the silent expression of violence is shown in subtle actions which violate the human dignity and get associated to symbolic actions, going over all the other ways and ends up being accepted as a normal aspect, naturalized by many people who live it, who practice it and watch it.

Invisible, this kind of violence goes by unnoticed by most of us and, in the health services, it gets present yet it is not perceived, by the delay on the feedback of a clinic analysis which retards the patient's expelling and agonizes the patient, in the procrastination of a diagnosis and the response about the feeling bad or even the total lack of information about the clinical picture for the interned patient about the reason for them staying there, many times feeling pain and suffering with the isolation of their social terms. The humanization tends to remind us that we need solidarity and social support. "It is an everlasting remembrance about our vulnerability and others' as well—A wake up call against violence” [15]. The denial or non recognition of the statute of the subject or person is a nocive effect of the symbolic violence, as a concrete possibility of no relationship [16].

Following these same principles, the humanized assistance to the child delivery is characterized by stimuli to breast feeding and the precocis linking, incentive to natural and vertical delivery, presence of companion chosen by the woman for the delivery process. This model opposes to the reductionism of comprehending the delivery as a pathologic phenomenon from the biomedical point of view [17], which has provoked the shifting of the caesareans in an epidemic, instead of keeping it as an important alternative for therapeutically indicated cases.

If we consider the violence issue as something against which the humanization struggle a big and important battle, an important issue to be considered is the right of the woman in delivery process to one companion as recommended by the WHO [18]: "A delivering woman must 
be accompanied by people she trusts and with whom she feels comfortable, her partner, her friend, a nurse or obstetrics nurse".

Another relevant aspect is the issue of pain. Reflections around the cutting down of pain during the delivery are not new. In the $19^{\text {th }}$ century there are registries of use of opium and, in the $20^{\text {th }}$ century, painkillers and also the resource of caesarean delivery. Around the far fetched 1950 's we conceived the delivery with no pain through a prophylactic method.

In 1990, the eastern techniques, mystic and psychological to prepare the women and the baby came to the scene. The background of those reflections, the delivery with no violence, became a reference for the humanization of the assistance which aims to make the delivery more and more natural and less invasive. "The presence of companion, the emotional support, the relief techniques, the team support, are not enough to eliminate the pain experience factor though, experience which not only gets related with the subjectivity of each woman, but, even more, with the self way how this pain is built by the culture" [17].

In the sense, it is perceived that some women try to control the emotions to be into certain cultural considered to be more proper-gestures and acts of despair, obeying to medical rules and accepting the advice of the team. Those ones who get out the Standards are considered to be decompensated and are blamed for the promotion of stress in the ambiance and in the professionals: to their state of imbalance and, in some cases, loss of consciousness is addressed to difficulties faced at the delivery.

Nevertheless, when it is possible that the idea that the pain is legitimate is shared among delivering patients and the team the establishment of benefits are really established: "The legitimating of the pain in a context that in principle is adverse, establishes a two way communication, reverse of which happens when a professional reduces the pain to the universal organic dimension; there is no possible negotiation, but otherwise, imposition and violence (...). The important to retain here is that the situations of decompensation are exactly those in which the respect to the physiological process of the woman and her decisions is replaced by the conventional: with no explanations, without negotiation margins, with disqualification and jeopardizing of the delivering woman. They are always neuralgic situations which bring about disrespect to the rights and symbolic violence" [17].

And why not to say silent violence? Many aspects belonging to the humanization of the delivery and the childbirth have been that target of effective governmental actions: right to appointments and prenatal exams, permanence of the companion in the delivery and post delivery, that the baby is immediately taken to their mother right after receiving the first podiatric cares, except in the cases when either the mother or the baby require special care, among other cases.

But there are other untouched issues yet and which are still part of the day-by-day of Brazilian public maternities: beds in the infirmaries which don't allow privacy for the household contact, not even for the mother and baby to be breastfed; women who are placed in the infirmaries indistinctly, better saying, women remain at the same infirmary: women with their babies breastfeeding them and living situations which are all predictable in the context whereas others immediately beside them cry out for either their baby who died at the birth or who have gone to intensive therapy because needed special care. Typical manifestations of silent violence, once they are institutionalized and naturalized practices by the professionals in the everyday work shift.

As for other sectors of assistance, at the hospital maternity it is also possible to check out the autonomy and the higher margins of power of the doctor if compared to other professionals. However they don't always show to be flexible and sensitive to the proposed changes aiming to humanize the assistance as these last ones.

We start to question then, about the relationship of the medical formation with the humanization of the assistance to the health of the woman. That is what we start to approach from this point.

\section{HUMANIZATION OF MEDICINE AND THE HUMANIZED ASSISTANCE TO THE WOMAN: PROPOSALS AND PERSPECTIVES}

In the ambiance of medical formation, several elements have been appointed by the studies of medical sociology, psychology and anthropology as important to be thought over the humanization of medicine. Some of them are: subjective dimension and the importance of affections in situations of suffering, pain and death; discussion on welcoming, importance of dialog and communication; care over the mental health of the health professional.

Other pertaining themes to the discussions around the humanization of medicine are the projects which concern the medical formation, having as its central target, giving back to medicine what it has lost as time went by. We will take as previously supposed that the doctor's formation is a neuralgic for the discussion on the humanization of health and assistance to the woman, neither the only nor the most important one. However, to a great extent, the identity and the profile of the professional gets defined during their formation and this is the fundamental issue of our object of reflection.

The passage of the $18^{\text {th }}$ century to the $19^{\text {th }}$ century was a very important epoch for the transition for the modern medicine which started to base itself on the anatomy- 
clinic model, due to the discoveries performed by the pathologic. In the $19^{\text {th }}$ century there was an explosion of knowledge and techniques and little by little the act of caring, comforting, consolation, welcoming which were part of the day-by-day of the doctor were being suppressed. The picture of sick patient assumes new representations: besides the aim of care, they become object of learning, studies and researches [1].

Until then, the doctor associated the scientific advances, arts, philosophy and history to the elaboration of diagnosis and conduction of treatment, in the fields of anatomy, pharmacology, pathology and clinic. That doctor didn't reduce their art of curing to one technique, their role was the one of alleviating the suffering and the pain of both patients' and their families', preparing them to the facing of death and acting preventively, through orientation to prevent getting sick and contagions.

The discovery of microbiology revolutionized the field of study of pathology, making it possible to develop laboratory analysis and other clinic methods. Little by little medications were being discovered and developed, rising the spectrum of actions and possibilities of treatment. Also the evolution of pathologic anatomy guided the medical interest to lesions as an explaining basis of sicknesses, making it possible to create classifying generalizations

"New objects are given to the medical knowledge, at the same time and at the point that the cognitive subject gets organized, modified and gets to work out in a different way. It was not, therefore, the conception of sickness that has changed at first, and right after it the way to recognize it; not even the system of signals that has been changed and right after that the theory; but all the collection and, more properly, the relationship of the sickness with this point of view to which it gets offered and that at the same time constitutes it” [1].

Flexner's model provoked a revolution into the medical education in the early $20^{\text {th }}$ century, producing an adaptation in the medical schools to the scientific and economic parameters of that epoch, with emphasis on the technical dimension, work specialization and fragmentation of knowledge [19]. These paradigmatic changes were enough to guide medicine in the parameters of the biomedical model.

In the international extension Flexner's Report cooperated into the reorganization and regulation of the working of medical schools, and moreover, provided the search of excellence in them. On the other hand, it eliminated completely all the proposals of attention to health and, based on scientific reasoning, it increased the dichotomy between learning of medicine and professional practice, as well as their applications and consequences in the health services [20].

Disturbances and insatisfactions about the model of teaching adopted since then provoked a wide debate in the end of the 1990's and the beginning of the year of 2000 in Brazil. The National Inter-institutional Commission of Medical Teaching (NICMT) had as its objective to construct proposals of changes to medical schools, reviewing theoretical landmarks and pedagogic practices, in order to develop, in its core, a new point of view to this formation. Using an innovative way to evaluate collectively, the focus of the commission was to shift the medical school to the formation of a committed Professional to the social demands into the treating of the patient [19]. We shall consider positive the transformations of the contemporary medicine concerning the auxiliary instruments to diagnosis and treatment. However, they were accompanied of a distancing of the sick patient, the excessive contact with exams, machines and procedures, exaggerated and invasive interventions and the inconsideration of psychosocial aspects.

The great proposal of humanization of the curricula of the colleges of medicine is repositioning the ethic dimensions and the related ones during the formation. This happens into the trans-disciplinary universe as a collective of subjects, which is generally called Humanities. It deals with reincluding the subjects (concepts and contents) of human sciences in order to make it possible to have a reflection about medical practice through other paths which are not only biologic, contemplating the social, cultural, psychological, philosophic aspects present in the pictures of pain, suffering, sickening and death.

In a final analysis, "the medical humanities allow the developing of a new comprehension of the living dimension and the person's suffering, incorporating the social reality and the individual experience into the meeting between the doctor and the patient. It is an integrated conception that aims to improve the doctors' communicative abilities and going deeply into the narrative about the ailment, searching news ways of promoting patients' [...] rethink not only the medical practice but also the formation in medicine, through the development of new ways into the continuing education and in the clinic activity" [21].

All these premises are also valid to the proposals of medical formation so that to contemplate, among other issues, the humanization of the assistance to the woman in the delivery and the childbirth. In this sense it is worth considering that the delivery has undergone modifications historically speaking: from a natural event, to the natural delivery to the medicalization and the institutionalization of the delivery, there is a historical path since the first practices of the midwives, beliefs and prayers up to our days when the technological advances and the development of the medicine have cooperated to the fall over of the rates of deliverer mortality and, mainly newborn death. Paradoxically, at the same time, the nowa- 
days deliverer became a sick person, a patient without rights over their own bodies and that, not rarely, unluckily, are disrespected as a human being and citizen, subject of rights and duties [22].

Among other consequences, these transformations introduced the masculine Picture and the medical dispositive as dominants, giving the woman's body scientific denomination, while symbolic elements of domination. The one which in the past was performed in the household ambiance, by midwives or godmothers, people of the pregnant women's trust or of recognized experience in the community, starts to be an event controlled by the biomedicine.

Since then, the assistance to the deliverer started to be of responsibility of a doctor specialized in obstetrics, Field of the medical sciences which cares for the human reproduction in the woman, as well as their health in the prenatal, delivery and child death. It's interesting to observe that this term comes from the Latin word, obstetrix, as a derivation of the verb obstare, which indicates the action of "staying by the side". In this sense, the obstetrician has the important role of being together the woman at this particular and special moment when a new life is being generated.

These changes have as their landmark the centuries $18^{\text {th }}$ and $19^{\text {th }}$, coinciding with the technological development of medicine as a whole and, which in the field of obstetrics, was also impulsed by the exaltation of motherhood [23].

There came so, the intervention by forceps and the horizontal delivery which are symbols of the art of medical obstetrics, favoring its acceptance as a technical and scientific subject. This factor contributed significantly so that the natural event of the delivery started to be considered a harmful, private, intimae and feminine event, not being lived in a public way anymore.

The $19^{\text {th }}$ century witnessed the development of new techniques of surgery, anesthetics and the use of cleanliness during the delivery process and, although even today there is a broad debate whether the delivery must be done simply by a midwife or an obstetric nurse, the event of birth was appropriated by medicine, became institutionalized and medicalized and it was fundamental for the development of such techniques. With the decreasing of the rates of mother/newborn death, the acceptance of the hospitalization and the improvement of the medical knowledge were made easier by the ideals of security credited to the figure of the doctor.

In Brazil, the development of the obstetrics hasn't happened in a distinct way of the one in Europe. In the colonial period, the midwives were the holders of the art of delivering, possessors of the empiric knowledge and practitioners of the mystic arts as a way to minimize the deliverers' suffering.
In Brazil the development and the evolution of the obstetrics science happened in a slow and gradual way, because of depending directly on either the immigration of foreign professionals or the comeback of some professional who had the chance to study in Europe. Soon the first colleges started to be inaugurated and the figure of the midwife was eliminated by the medical science.

The church and medicine made an alliance for the domination and medicalization of the female body-the first one dealing with the care of the soul and the second one of the body, by the means of the ideals around the female figure as an object at service of reproduction with the determined role of dedicating exclusively to the household life, being the suffering of the delivery seen as an opportunity to get purified and redeeming from sins [22]. The ownership of the female body on medicine's behalf resulted in a culture which transformed the delivery into a surgical action, the pregnancy and menopause into a sort of sickness, the menstruation into a chronic event, all of them subjected to be medicalized.

This conception was taken along until the post war period when the lifestyles were radically altered in all the levels. The psycho social problems increased, the demographic control started to be a need to the restructuring of life in the cities. If the end of the $19^{\text {th }}$ century was remarked by the competition between laymen and scientists as for the care around the delivery, the $20^{\text {th }}$ century witnessed the emancipation of the woman impulsed by the feminist movements and, because of so, the consolidation of the medicalization and hospitalization process of delivery happens in the middle of the $20^{\text {th }}$ century.

Nowadays the delivery has been considered an event which is far away from the woman an epoch when there are strong and wide bioethics debates around genetic engineering, in vitro fertilization and fetal medicine. We have watched the indiscriminated use of technology which has transformed the delivery in an event far from the woman, about which she has no more privacy or autonomy.

We have also watched the tiredness of the obstetrics doctor to deal with the complex bio-psychosocial realities which surround the event of reproduction, pregnancy, delivery and child death contemporarily. Women who have a problem in their pregnancy, be it because of economic or household issues which impeach them to keep track of their prenatal program or sometimes because it was not a planned event itself.

The absence of a partner or companion, not rarely generates insecurity into the pregnant woman who starts to require from the doctor a relationship of trust which is not found all the time, once that, as we have already seen, the biomedical formation is much more focused into the technique and the biological plan, than into the ethic and relationship dimensions. 
Therefore the search for specialization in obstetrics has been falling down in number of cases, for similar reasons, for example, the search for specialization in podiatric [24]: there is one transition moment in the structuring of the family which affects directly the professions that in one way or another are related to it.

It is in this sense that the courses of medicine in Brazil have proposed more and more the re-inclusion of the contents of the human sciences into the medical curricula, with the objective of giving back to the doctor what has been lost along time: the art of care which in, the specialization of obstetrics, is fundamental to deal with the feminine universe into everything it comprises currently, especially, the essence of the obstetrics science, the staying side by side, as we have described above.

There are initiatives which show that the humanization of medicine has provoked positive effects into the formation of new doctors, especially in what deals with the humanization of the delivery, as reported by Rebello e Neto [25]: the perception of the medical students has been altered, which is fundamental for the effectiveness of the current policies of humanization.

\section{CONCLUSION}

We must consider as positive the changes of contemporary medicine in the situations dealing with the auxiliary instruments to the diagnosis and treatment. However, they have come together from the distance of the person of the sick one, the excessive contact with checkups, machines and procedures, exaggerated and invasive interventions, and inconsideration of psychosocial aspects.

The great proposal of humanization the curricula of medical schools is repositioning the ethic dimensions and the like during the formation. We consider it to be possible in the future if it is associated with another also fundamental change, the paradigmatic change of the biomedical model to the bio-psychosocial model.

The scientific reasoning called bio-medic is shown as a systematically organized collection around five theoretical basic elements: morphology (anatomy), physiology, diagnosis (sickness), intervention (medicine oriented or surgical) and the medical doctrine (treating the lesions) [26]. This biomedical reasoning may be summarized from the structured ideals into a scientific logic, which are: check up universal validity to the knowledge; naturalize the models of the machines applying them to the human body; and isolate parts which pre conceive the overall work.

Even though the medical reasoning has favored the inclusion into the medicine in the overall study and the models of natural sciences, resulting the objectivities of the sickening processes and the naturalization of its object of study, this becomes a classic way of silent violence, for it makes possible the exclusion of subjectivity of the sick one and favors the generalization of sicknesses and subjects [14]. With these situations dichotomies are installed: objective/subjective; sickness/sick person; theory/practice; individual/social; technology/human factor. The subjective factors, therefore, start to be seen as anomalies [27], as obstacles which impeach the doctor for exercising their competence and professional ethics.

As said by Leite [28], "the doctor still exercises some power which is visible in one omnipotence over the destiny of the human life, sectioning the patient's body in such a way that both-doctor and sick person-end up losing the domain over the 'organic overall'."

This way we get face to face with a great stalemate: the current model (bio-medical) which guides the medical formation, develops health practices which don't follow important principles of SUS: "they [the bio-medical professionals] are 'charged' by the sick ones and for their ethic mission of healers, and now by SUS and by PSF, for them to have whole attention to health, but their recent knowledge and tradition are centered in something which is alike the contrary of the wholeness” [29].

On the other hand, the psychosocial model, contemplates the plurality, presupposing the overcoming of the biological specification of the body which, in the sickening, brings about "social production condition, and the space for inter subjective exchanges" which are weaved "over, into and beyond the biological bodies" [30].

We have advanced in the epistemological aspect according to a biomedical model and it is fundamental to go on its overcoming. Replacing it by another paradigm in health would contemplate non objectivable aspects, especially concerning the relationship doctor-patient.

The bio-psychosocial model, because of being based on the health concept of the WHO-bio-psychosocial welfare-is presented as an alternative to biomedicine and as more appropriate to the facing of complex demands which emerge in the Field of health as we have stated in previous work [31].

It is a model that "besides of comprehending, physical psychological and social dimensions, providing a whole view of the human being and, when incorporated to the formation of the doctor, points out to the need that the professional keeps in a constant process of formation to beyond the technical learning, perfecting of the instrumental abilities. The related capacities also evolve and allow the doctor to establish proper and effective connection and communication" [32].

These indispensable presupposed factors, to think of the re-humanization of the medicine [33], are also absolutely necessary to the humanization of health and, to our point of view, eventually, for the humanization of the assistance to the woman in the delivery and the childbirth. They are interlaced and any impossibility of effectivation of one of those will compromise the other one. 
Thus we understand that the biggest current challenge is promoting the discussion linked to the themes approached here, thinking about possible solutions which come at last to promote the coming around of the obstetrics doctor and the pregnant woman, seeing her above it all, as a person who feels, thinks, gets agonized, desires and can cooperate in the process of generating, delivering, welcoming and caring.

\section{REFERENCES}

[1] Foucault, M. (2004) Onascimento da clínica. 6th Edition, Tradução de Machado, Forense Universitária, R. Rio de Janeiro, 95.

[2] Brasil, M.S. (2000) Programa nacional de humanização da assistência hospitalar, Brasília.

[3] Brasil, M/S. (2001) Parto, aborto e puerpério: Assistência humanizada à mulher.

[4] Brasil, M.S. (2002) Programa de Humanização do parto. Humanização no pré-natal e nascimento.

[5] Minayo, M.C.S. (2007) O desafio do conhecimento. Hucitec, São Paulo, 168.

[6] Brasil, M.S. (2000) $11^{\text {a }}$ Conferência Nacional de Saúde: O Brasil falando como quer ser tratado: efetivando o SUS: acesso, qualidade e humanização na atenção à saúde com controle social.

[7] Brasil, M.S. (2003) Política nacional de humanização. Documento base para gestores e trabalhadores do SUS. Saúde, 6 .

[8] Onocko Campos, R. (2004) Mudando os processos de subjetivação em prol da humanização da assistência. Ciência e Saúde Coletiva, 9, 15-29.

[9] Puccini, P.T. and Cecílio, L.C.O. (2004) A humanização dos serviços e o direito à saúde. Cadernos de Saúde Pública, 20, 1342-1353.

[10] Rios, I.C. (2009) Humanização: a essência da ação técnica e ética nas práticas de saúde. Revista Brasileira de Educação Médica, 33, 253-261.

[11] Foucault, M. (2007) Microfísica do poder. Graal, Rio de Janeiro.

[12] Rios, I.C. (2007) Ser e fazer diferente... é possível provocar o desejo? Interface-Comunicação, Saúde, Educação, 11, 628-630.

[13] Deslandes, S.F. (2004) Análise do discurso oficial sobre a Humanização da assistência hospitalar. Ciência e Saúde Coletiva, 9, 7-14.

[14] Leite, L.C. (2010) Relatório final de Pesquisa: Violência, juventude e saúde mental. IPUB/UFRJ, Rio de Janeiro, 2009.

[15] Campos, G.W.S. (2005) Humanização da Saúde: Um projeto em defesa da vida? Interface-Comunicação, Saúde e Educação, 9, 389-406.

[16] Deslandes, S.F. (2004) A humanização e a construção política do lugar do sujeito no processo comunicacional. $\mathrm{Ci}$ - ência e Saúde Coletiva, 9, 15-29

[17] Tornquist, C.S. (2003) Paradoxos da humanização em uma maternidade no Brasil. Cadernos de Saúde Pública, 19, S419-S427.

[18] WHO (World Health Organization) (1998) World Health Day. Safe motherhood. WHO, Geneva, 13.

[19] Merhy, E.E. and Aciole, G.G. (2003) Uma nova escola médica é possível? Aprendendo com a CINAEM as possibilidades da construção de novos paradigmas para a formação em medicina. Pro-posições, 14, 1-22.

[20] Pagliosa, F.L. and DaRos, M.A. (2008) O Relatório Flexner: Para o bem e para o mal. Revista Brasileira de Educação Médica, 32, 492-499

[21] Deslandes, S.F. (2006) Humanização dos cuidados em saúde: Conceitos, dilemas e práticas. Fiocruz, Rio de Janeiro.

[22] Seibert, S.L., Barbosa. J.L.S., Santos, J.M. and Vargens, O.M.C. (2005) Medicalização x humanização: O cuidado ao parto na história. Revista de Enfermagem da UERJ, 13, 245-251.

[23] Vieira, E.M. (2002) A medicalização do corpo feminino. FIOCRUZ, Rio de Janeiro.

[24] Barreiro, F. (2013) Notas sobre a redução do número de pediatras.

http://www.sbp.com.br/show_item2.cfm?id_categoria=65 \&id_detalhe=2193\&tipo_detalhe $=$ s

[25] Rebello, M.T.M.P. and Neto, J.F.R. (2012) A Humanização da Assistência ao Parto na Percepção de Estudantes de Medicina. Revista Brasileira de Educação Médica, 36, 188-197. doi:10.1590/S0100-55022012000400006

[26] Camargo Jr., K.R. (1997) A Biomedicina. Physis: Revista de Saúde Coletiva, Rio de Janeiro, 7, 45-68.

[27] Guedes, C.R., Nogueira, M.I. and Camargo Jr., K.R. (2006) A Subjetividade como anomalia: Contribuições epistemológicas para a crítica do modelo biomédico. Ciência $e$ Saúde Coletiva, 11, 1093-1103. doi:10.1590/S1413-81232006000400030

[28] Leite, L.C. (1998) A razão dos invencíveis. UFRJ, Rio de janeiro, 33.

[29] Tesser, C.D. and Luz, M.T. (2008) Racionalidades Médicas e Integralidade. Ciência e Saúde Coletiva, 13, 195206.

[30] Onoko Campos, R. (2003) Reflexões sobre o conceito de humanização em saúde. Saúde em debate, Rio de Janeiro, 27, 123-130.

[31] Mello, D.R.B., Leite, L.C., Campos, M.G.S.C. and Alves Filho, R.C. (2012) Alçando voo: A experiência de ampliar o diálogo entre psicologia e medicina. Revista Brasileira de Educação Médica, 36, 234-242.

[32] Mello, D.R.B. (2010) Violência e a inclusão deste tema nos currículos médicos: Breves reflexões. Perspectiva, 4. http://seer.perspectivasonline.com.br.

[33] Gallian, D.M.C. (2012) A (re)humanização da Medicina Disponível em. http://www.unifesp.br/dpsiq/polbr/ppm/especial02a.htm 